\title{
NGHIÊN CÚUU ÚNG DỤNG SÓNG CAO TẦN TRONG ĐIỀU TR! SUY TĨNH MẠCH MẠN TÍNH CHI DƯỚI TẠI BỆNH VIỆN QUỐC TẾ MINH ANH
}

Nguyễn Hoài Nam*, Đào Duy Phuoong*, Trần Minh Bảo Luân*

\section{TÓM TÁT}

Bệnh nhân suy tĩnh mạch mạn tính chi dưới được điều trị bằng sóng cao tần tại Bệnh viện Quốc tế Minh Anh. Tỷ lệ nữ/nam là 3/1 (nữ chiếm 74,9\%), tuổi trung bình là $56 \pm 4,8$ tuổi, phân độ $\mathrm{CEAP}$ cho thấy độ $\mathrm{C} 2, \mathrm{C} 3$ chiếm đa số. Tĩnh mạch hiển lớn tắc hoàn toàn trên siêu âm doppler kiểm tra sau 1 tháng chiếm tỷ lệ là 95\%. Biến chứng: không có biến chứng huyết khối tĩnh mạch sâu, dị cảm 20 trường hợp (8\%), xuất huyết $\mathrm{khu}$ trú vùng đùi 38 trường hợp $(15 \%)$, xuất huyết rộng vùng đùi 1 trường hợp $(0,4 \%) .226$ trường hợp $(90 \%)$ đau rất ít hoặc không đáng kể, 20 trường hợp $(8 \%)$ đau trung bình và 5 trường hợp $(2 \%)$ đau nhiều sau can thiệp. Đa số bệnh nhân đều hài lòng sau thủ thuật $96,2 \%$.

\section{I. ĐẶT VẤN ĐỀ}

Suy tĩnh mạch mạn tính chi dưới là sự suy giảm chức năng đưa máu trở về tim của hệ thống tĩnh mạch chân, dẫn đến hiện tượng máu ứ đọng lại sẽ gây ra những biến đổi về huyết động và biến dạng tổ chức mô xung quanh, gây ra dãn lớn các tĩnh mạnh nông, viêm tĩnh mạch nông huyết khối hay huyết khối tĩnh mạch sâu.

Suy tĩnh mạch có thể xảy ra ở bất kỳ tĩnh mạch nào trên cơ thể, nhưng trên thực tế phần lớn các trường hợp mắc phải đều xảy ra ở chi dưới do chịu ảnh hưởng của trọng lực khi người bệnh phải đứng nhiều. Suy tĩnh mạch mạn tính chi dưới thường ít nguy hiểm, nhưng gây cho người mắc bệnh cảm giác khó chịu, ảnh hưởng đến chất lượng cuộc sống. Đây là bệnh lý khá thường gặp ở các nước phương Tây, ước tính khoảng 5- 30\% dân số mắc bệnh, trong đó $70 \%$ là nữ giới và chiếm $2 \%$ ngân sách chi tiêu cho y tế. Bệnh hay gặp ở người có thói quen hay nghề nghiệp phải đứng hoặc ngồi lâu, phụ nữ mang thai sanh nở nhiều, béo phì và người lớn tuổi [5]. Tại Việt Nam, theo ghi nhận tại các phòng khám khoảng $62 \%$ bệnh nhân có biểu hiện của suy tĩnh mạch mạn tính chi dưới. [4]

Hiện nay, ngoài điều trị nội khoa như thay đổi lối sống, mang vớ áp lực, dùng các thuốc trợ tĩnh mạch và phẫu thuật stripping, còn áp dụng kỹ thuật ít xâm lấn mang lại hiệu quả cao đó là can thiệp tĩnh mạch bằng sóng cao tần gọi tắt là RFA (Radio Frequency Ablation). Nguyên lý của phương pháp này là nhiệt độ cao tác dụng trực tiếp lên thành tĩnh mạch $\left(120^{\circ} \mathrm{C}\right)$ dể làm teo và xơ hóa lòng tĩnh mạch, từ đó gây tắc tĩnh mạch hiển lớn và loại bỏ dòng trào ngược. Năm 1998, can thiệp tĩnh mạch hiển bằng sóng cao tần được giới thiệu đầu tiên tại Châu Âu [7]. Đến năm 2011, RFA tĩnh mạch hiển được ứng dụng lần đầu tại Việt Nam và bệnh viện quốc tế Minh Anh cũng đã thực hiện kỹ thuật này từ 2014 đến nay. Tuy nhiên, chưa có số liệu thống kê cụ thể về hiệu quả của việc ứng dụng phương pháp này tại đây. Vì vậy, chúng tôi tiến hành thực hiện nghiên cứu ứng dụng sóng cao tần trong điều trị suy tĩnh mạch chi dưới tại Bệnh viện Quốc tế Minh Anh.

\section{II. ĐỐI TƯợng VÀ PHƯƠNG PHÁP NGHIÊN CÚU}

\section{Thiết kế nghiên cứu: mô tả loạt ca.}

Đối tượng nghiên cứu: bệnh nhân được chẩn đoán suy tĩnh mạch mạn tính chi dưới và

* Bệnh viện quốc tế Minh Anh

Người chịu trách nhiệm khoa họ: PGS.TS. Nguyên Hoài Nam Ngày nhận bài: 01/05/2018 - Ngày Cho Phép Đăng: 20/05/2018

Phản Biện Khoa học: PGS.TS. Đặng Ngoc Hùng GS.TS. Lê Ngoc Thành 
được điều trị bằng phương pháp đốt sóng cao tần tại Bệnh viện quốc tế Minh Anh từ tháng 01/2014 đến tháng 01/2018.

Tiêu chuẩn chọn bệnh:

Bệnh nhân suy tĩnh mạch chi dưới có triệu chứng ảnh hưởng chất lượng cuộc sống và có dòng trào ngược tĩnh mạch hiển lớn trên siêu âm Doppler, đã được điều trị bằng thuốc trợ tĩnh mạch và vớ áp lực nhưng không cải thiện. [8]

Suy tĩnh mạch chi dưới từ độ 2 trở lên theo phân loại lâm sàng CEAP.

Tiêu chuẩn loại trừ:

Huyết khối tĩnh mạch sâu.

Tĩnh mạch hiển lớn ngoằn ngoèo, nằm sát $\mathrm{da}$ và/hoặc có huyết khối bên trong.

Đường kính tĩnh mạch hiển lớn $<3 \mathrm{~mm}$ và/hoặc $>12 \mathrm{~mm}$. [8]

\section{KẾT QUẢ NGHIÊN CÚU}

Từ tháng 01/2014 đến 01/2018, có 251 bệnh nhân tại Bệnh viện quốc tế Minh Anh được chẩn đoán suy tĩnh mạch mạn tính chi dưới và can thiệp điều trị bằng sóng cao tần.

Đặc điểm chung

Giới tính: Nữ: 188 trường hợp (74,9\%); Nam: 63 trường hợp $(25,1 \%)$

Tuổi: trung bình là $56 \pm 4,8$ tuổi $(25-74)$, trong đó độ tuổi 40 - 60 chiếm 75\%.

Nghề nghiệp đứng lâu, ngồi nhiều (trên 6-8h/ ngày): $81 \%$

Bệnh nhân nữ sanh $\geq 3$ con: $60 \%$.

Tiền sử gia đình suy tĩnh mạch hay huyết khối tĩnh mạch chi dưới: $28 \%$

Đặc điểm lâm sàng

Phân loại lâm sàng CEAP: độ $\mathrm{C} 2$ chiếm tỷ lệ cao nhất là 76,9\%. Độ C3, C4, C5, C6 chiếm tỷ lệ lần lượt là $14,33 \%, 7,17 \%, 1,2 \%$ và $0,4 \%$
Triệu chưng lâm sàng

\begin{tabular}{|l|c|c|}
\hline \multicolumn{1}{|c|}{ Triệu chứng } & Số bệnh nhân & Tỷ lệ \% \\
\hline Đau, nặng chân & 251 & 100 \\
\hline Vọp bẻ, chuột & 128 & 50,1 \\
\hline Dãn tĩnh mạch & 89 & 35,5 \\
\hline Phù chân & 55 & 21,9 \\
\hline Tê bàn chân & 36 & 14,3 \\
\hline Chàm hóa & 21 & 8,4 \\
\hline Loét chân & 1 & 0,4 \\
\hline
\end{tabular}

Bảng 1. Phân bố bệnh nhân theo triệu chưng lâm sàng

\section{Kết quả can thiệp bằng đốt sóng cao tần}

Trong 251 trường hợp của chúng tôi:

Nhóm 1: có 162 bệnh nhân được thực hiện can thiệp tĩnh mạch hiển lớn bằng sóng cao tần kết hợp lấy bỏ tĩnh mạch nông dãn tại chổ theo phương pháp Muller.

Nhóm 2: có 89 bệnh nhân chỉ can thiệp TM hiển lớn bằng sóng cao tần đơn thuần.

\begin{tabular}{|l|c|c|}
\hline Kết quả RFA & Nhóm 1 & Nhóm 2 \\
\hline Đau vết mổ: & & \\
\hline Đau ít & $90 \%$ & $58,4 \%$ \\
\hline Đau vù̀a & $8 \%$ & $30,2 \%$ \\
\hline Đau nhiều & $2 \%$ & $11,4 \%$ \\
\hline Tai biến-biến chứng: & & \\
\hline Dị cảm - tổn thuoòng TK & $8 \%$ & $13,6 \%$ \\
\hline Xuất huyết da & & \\
\hline XH khu trú & $15 \%$ & $81,3 \%$ \\
\hline XH lan rộng & $0,4 \%$ & $6,5 \%$ \\
\hline Thò̀i gian nằm viện & & \\
\hline 24 giò̀ & $86,5 \%$ & $47,9 \%$ \\
\hline 24 - 48 giò̀ & $13,5 \%$ & $52,1 \%$ \\
\hline
\end{tabular}

Bảng 2: kết quả sau thủ thuật RFA tĩnh mạch hiển lớn 


\section{Kết quả sau 01 tháng}

Hiệu quả xo hóa: tắc hoàn toàn tĩnh mạch hiển lớn và không còn dòng chảy chiếm tỷ lệ cao nhất là $95 \%$, có $5 \%$ tắc không hoàn toàn, còn dòng chảy nhỏ.

Mức độ hài lòng của bệnh nhân: tương đối hài lòng chiếm tỷ lệ cao nhất là $75 \%$, hoàn toàn hài lòng chiếm $21,2 \%$, không hài lòng chiếm $3,8 \%$, không có trường hợp phản đối hay hối tiếc.

\section{BÀN LUẬN}

\section{* Đặc điểm chung:}

Trong nghiên cứu của chúng tôi, giới nữ chiếm 74,9\% nhiều hơn so với giới nam là $25,1 \%$. Kết quả này tương tự như $\mathrm{y}$ văn và cũng gần giống như ghi nhận của chúng tôi trong nghiên cứu trước đây nam chiếm $20 \%$, nữ chiếm $80 \%$ [4].

Về các yếu tố nguy cơ: số liệu của chúng tôi ghi nhận $81 \%$ số trường hợp có nghề nghiệp đứng lâu hay ngồi nhiều, bệnh nhân nữ sanh nhiều hơn 3 con chiếm $60 \%$ và tiền sử gia đình bệnh tĩnh mạch $28 \%$ trường hợp. Theo nghiên cứu của Nguyễn Trung Anh, cho thấy giới nữ chiếm ưu thế với $75,7 \%$; trong đó yếu tố nguy cơ liên quan nghề nghiệp 87,1\%, sanh hơn 3 con $73,6 \%$ và tiền sử gia đình $30,7 \%$. Nghiên cứu của chúng tôi cũng như tác giả trên đều cho thấy: nghề nghiệp đòi hỏi đứng lâu, ngồi nhiều và vấn đề thai sản ở nữ giới là yếu tố nguy cơ thường gặp nhất. [1]

Nghiên cứu của chúng tôi ghi nhận tuổi cao nhất là 74 tuổi, thấp nhất là 25 tuổi, trung bình là $56 \pm 4,8$ tuổi, trong đó độ tuổi 40 - 60 chiếm $75 \%$. So với nghiên cứu của Cao Việt Cường ghi nhận tuổi trung bình là 50,9 tuổi, cao nhất là 76 tuổi, thấp nhất là 25 tuổi [2], kết quả này cũng tương tự với báo cáo của nhiều tác giả khác. Điều này cho thấy, dù bệnh nhân có các yếu tố nguy cơ như: nghề nghiệp đòi hỏi phải đứng lâu, ngồi nhiều và nữ giới sinh nở nhiều lần chiếm tỷ lệ cao, nhưng bệnh vẫn chủ yếu gặp nhiều ở độ tuổi 4060 tuổi. Nên có thể cho rằng bệnh nhân có các yếu tố nguy cơ cần thời gian đủ dài nhất định mới biểu hiện bệnh.

* Đặc điểm lâm sàng

Hai triệu chứng là đau, nặng chân và vọp bẻ, chuột rút chiếm tỷ lệ cao nhất lần lượt là $100 \%$ và $50,1 \%$, kế đến là biểu hiện dãn tĩnh mạch nông ngoài da với tỷ lệ 35,5\%. Trong khi đó, nghiên cứu về các đặc điểm lâm sàng trước đây của chúng tôi ghi nhận triệu chứng dãn tĩnh mạch chiếm tỷ lệ cao nhất là $100 \%$, kế đến là đau, nặng mõi chân $86 \%$ và phù chân chiếm $69,2 \%$ [4]. So với nghiên cứu của tác giả $\mathrm{S}$. Subramonia cho thấy đau, nặng mõi chân luôn luôn hiện diện ở bệnh nhân đến khám bệnh và phù chân $97,9 \%$.[9]

Kết quả nghiên cứu của chúng tôi và tác giả khác cho thấy tỷ lệ các triệu chứng thay đổi khá nhiều. Tuy nhiên, điểm chung vẫn là: triệu chứng đau, nặng mõi chân gặp nhiều nhất, kế đến có thể là biểu hiện dãn tĩnh mạch nông ngoài da và phù chân là ít nhất.

* Kết quả can thiệp tĩnh mạch hiển lớn bằng sóng cao tần

182 bệnh nhân ở nhóm chỉ thực hiện RFA tĩnh mạch hiển đa số đau ít không đáng kể $90 \%$ và chỉ $2 \%$ đau nhiều. Trong khi 89 bệnh nhân được kết hợp phẫu thuật Muller lấy bỏ tĩnh mạch dãn tại chổ thì mức độ đau thay đổi đáng kể chỉ 58,4\% đau ít và $30,2 \%$ đau vừa, đau nhiều tăng đáng kể đến $11,4 \%$.

Tác giả Lê Phi Long cũng như một số tác giả khác đều ghi nhận mức độ đau ít trên nhóm bệnh nhân RFA tĩnh mạch hiển đơn thuần chiếm tỷ lệ rất cao, nhóm kết hợp phẫu thuật Muller có mức độ đau trung bình và nhiều cao hơn; Và khi so sánh cả hai nhóm này với phẫu thuật stripping 
kinh điển đều cho thấy mức độ đau ít hơn đáng kể $(\mathrm{p}<0,05)[3]$. Điều này có vẽ được xem như là hiển nhiên về mặt kỹ thuật thực hiện thủ thuật, tuy nhiên cũng đã được chứng minh thêm qua số liệu nghiên cứu của chúng tôi cũng như các tác giả khác.

\begin{tabular}{|l|c|c|c|}
\hline Tai biến-biến chứng & Merchant R. F. [8] & Lê Phi Long [3] & Chúng tôi \\
\hline Huyết khối tĩnh mạch sâu & $1 \%(3 / 286)$ & $0 \%(0 / 70)$ & $0 \%(0 / 251)$ \\
\hline Dị cảm & $15 \%(43 / 286)$ & $16,9 \%(23 / 70)$ & $8 \%(4 / 251)$ \\
\hline Xuất huyết lan rộng mặt trong đùi & $2,1 \%(6 / 286)$ & $3 \%(2 / 70)$ & $0,4 \%(1 / 251)$ \\
\hline
\end{tabular}

\section{Bảng 3: So sánh tai biến và biến chứng}

Rõ ràng can thiệp tĩnh mạch hiển lớn bằng sóng cao tần (RFA) với tai biến và biến chứng rất ít và nếu có cũng chỉ là các biến chứng nhẹ thoáng qua. Rất ít báo cáo cho thấy có biến chứng nguy hiểm đó là huyết khối tĩnh mạch chậu - đùi. Các báo cáo gần đây cũng như nghiên cứu của chúng tôi và tác giả Lê Phi Long cũng không ghi nhận biến chứng này. Nhờ siêu âm doppler khảo sát và tầm soát để lựa chọn bệnh nhân không có huyết khối trong lòng tĩnh mạch nông cũng như tĩnh mạch hiển và về mặt kỹ thuật thực hiện cần tuân thủ tuyệt đối chỉ đốt cách xa chỗ nối tĩnh mạch hiển - đùi $2 \mathrm{~cm}$.

Ngoài ra, để hạn chế biến chứng dị cảm, xuất huyết thì việc tiêm dung dịch cách nhiệt phải được quan sát kỹ trên siêu âm, phải bao bọc được toàn bộ tĩnh mạch và tránh đâm thũng tĩnh mạch khi tiêm dung dịch cách nhiệt

Về thời gian nằm viện sau thủ thuật, nghiên cứu của chúng tôi cũng như tác giả ElKaffas $\mathrm{K}$. $\mathrm{H}$. đều cho thấy nhóm RFA tĩnh mạch hiển đơn thuần có thời gian nằm viện ngắn hơn nhóm có kết hợp phẫu thuật Muller. Và khi tác giả này so sánh với nhóm được phẫu thuật stripping sự khác biệt này càng rõ ràng hơn $(\mathrm{p}=0,01)$. [7]

Qua đó, chúng tôi nhận thấy với những ưu điểm vượt trội về kết quả sớm ngay sau thủ thuật của RFA so với phẫu thuật stripping kinh điển: ít đau, ít tai biến và biến chứng, rút ngắn thời gian nằm viện. Điều này góp phần làm giảm chi phí điều trị, nhanh chóng đưa bệnh nhân trở về hoạt động lao động hàng ngày và cũng góp phần làm giảm quá tải bệnh viện.

\section{Kết quả 01 tháng sau can thiệp tĩnh mạch hiển lớn}

Trong 251 trường hợp của chúng tôi, siêu âm doppler kiểm tra 1 tháng sau thủ thuật cho thấy $95 \%$ tắc hoàn toàn tĩnh mạch hiển lớn, chỉ $5 \%$ còn dòng chảy nhỏ và không có hiện tượng trào ngược. Tác giả Lê Phi Long ghi nhận tắc tĩnh mạch hoàn toàn đạt $90 \%$ [3]. Tác giả Alan $\mathrm{M}$. Dietzet ghi nhận $100 \%$ tắc tĩnh mạch hoàn toàn trong nghiên cứu của mình [5]. Kết quả của chúng tôi cũng như các tác giả trên cho thấy hiệu quả rất tốt của RFA trong việc loại bỏ dòng trào ngược tĩnh mạch hiển - đùi.

Về mức độ hài lòng của bệnh nhân sau thủ thuật: chúng tôi ghi nhận $21,2 \%$ hoàn toàn hài lòng và $75 \%$ tương đối hài lòng, chỉ 3,8\% không hài lòng vì vẫn còn dị cảm do tổn thương thần kinh cảm giác nông do phẫu thuật Mulller hay cảm giác căng tức dọc đường đi tĩnh mạch hiển. So với nghiên cứu của tác giả $S$ Subramonia, ghi nhận số điểm trung bình về mức độ hài lòng ở nhóm RFA là 10 điểm cao hơn so với 8,7 điểm ở nhóm mổ Stripping $(\mathrm{p}=0,016)$ [9]; nghiên cứu của tác giả Lê Phi Long cũng cho thấy $76 \%$ bệnh nhân hài lòng [3]. Như vậy, can thiệp tĩnh mạch hiển bằng sóng cao tần (RFA) có hiệu quả cao về điều chỉnh rối loạn chức năng tĩnh mạch cũng như mức độ hài lòng của bệnh nhân. 


\section{KẾT LUẬN}

Phương pháp can thiệp tĩnh mạch hiển lớn bằng sóng cao tần (RFA) nhằm loại bỏ dòng trào ngược tĩnh mạch hiển - đùi có hiệu quả cao về mặt điều trị. Bên cạnh đó, thủ thuật được thực hiện chỉ với vết rạch da rất nhỏ nên ít đau, tính thẫm mỹ cao, an toàn và giúp cải thiện các triệu chứng lâm sàng, góp phần nâng cao chất lượng sống cho bệnh nhân nên đạt được tỷ lệ hài lòng của bệnh nhân khá cao.

\section{TÀI LIỆU THAM KHẢO}

1. Nguyễn Trung Anh (2016). "Nghiên cứu đặc điểm lâm sàng, cận lâm sàng, kết quả điều trị suy tĩnh mạch chi dưới mạn tính của phương pháp gây xơ bằng thuốc và Laser nội tĩnh mạch". Luận án Tiến sĩ Y học. Viện nghiên cứu Khoa học Y Dược lâm sàng 108. Hà Nội.

2. Cao Việt Cường (2012). "Nghiên cứu ứng dụng phương pháp gây xơ tĩnh mạch bằng chất tạo bọt dưới hướng dẫn của siêu âm trong điều trị suy tĩnh mạch mạn tính chi dưới". Luận văn Thạc sĩ $\mathrm{Y}$ học. Trường Đại học Y Hà Nội. Hà Nội.

3. Lê Phi Long (2011). "Đánh giá kết quả ứng dụng kỹ thuật đốt sóng cao tần trong điều trị dãn tĩnh mạch chân". Luận văn Thạc sĩ Y học. Đại học Y Dược TPHCM. TP Hồ Chí Minh.
4. Nguyễn Hoài Nam (2012). "Nghiên cứu biểu hiện dịch tể học lâm sàng của bệnh suy tĩnh mạch chi dưới mạn tính". Tạp chí Y học Thành phố Hồ Chí Minh. 16(1). tr. 202-205.

5. Alan M. Dietzek (2007). "Endovenous Radiofrequency Ablation for the Treatment of Varicose Veins". Vascular. 15(5). pp. 255-261.

6. Jose I. Almeida and Jeffrey K. Raines (2012). "Varicose Veins". Haimovici' Vascular Surgery Sixth Edition. pp. 11211130.

7. Khaled Helmy ElKaffas, et al (2010). "Great saphenous vein radiofrequency ablation versus standard stripping in the management of primary varicose veins - a randomized clinical trial". Angiology. 62(1). pp. 49-54.

8. Robert F. Merchant and Robert F. Kistner (2009). "Radiofrequency treatment of the incompetent saphenous vein ". Handbook of venous disorders. 3rd edition. pp. 409-417.

9. S. Subramonia and T. Lees (2010). "Randomized clinical trial of radiofrequency ablation or conventional high ligation and stripping for great saphenous varicose veins". British Journal of Surgery. 97. pp. 328-336. 